\title{
COVID-19 pandemic and its psychological impact among healthy Portuguese and Spanish nursing students
}

\author{
Carlos Laranjeira' ${ }^{1}$, Ana Querido², Goreti Marques ${ }^{3}$, Mafalda Silva, Daniela Simões ${ }^{5}$, Luísa Gonçalves ${ }^{6}$, Rita Figueiredo \\ ${ }^{1}$ School of Health Sciences of Polytechnic of Leiria, Leiria, Portugal; Center for Innovative Care and Health Technology (ciTechCare), Polytechnic of \\ Leiria, Leiria, Portugal; RECI (Research in Education and Community Intervention), Viseu, Portugal, 2 School of Health Sciences of Polytechnic of Leiria, \\ Leiria, Portugal; Center for Innovative Care and Health Technology (ciTechCare), Polytechnic of Leiria, Leiria, Portugal; NursID: Innovation \& \\ Development in Nursing - Research Group, CINTESIS - Center for Health Technology and Services Research, Porto, Portugal, 3 NursID: Innovation \& \\ Development in Nursing - Research Group, CINTESIS - Center for Health Technology and Services Research, Porto, Portugal; Santa Maria Health \\ School, Porto, Portugal, 4 Piaget School of Health, Vila Nova de Gaia, Portugal; Catholic University of Portugal, Institute of Health Sciences, Center for \\ Interdisciplinary Research in Health (CIIS), Porto, Portugal, 5 Santa Maria Health School, Porto, Portugal, 6 S. José de Cluny Nursing School, Funchal, \\ Portugal, ${ }^{7}$ NursID: Innovation \& Development in Nursing - Research Group, CINTESIS - Center for Health Technology and Services Research, Porto, \\ Portugal; S. José de Cluny Nursing School, Funchal, Portugal \\ Keywords: anxiety, nursing students, stress, covid19 \\ https://doi.org/10.52965/001c.24508
}

\section{Health Psychology Research}

Vol. 9, Issue 1, 2021

Few studies have explored the impacts of COVID-19 and lockdown on the mental health of undergraduate nursing students. This study aimed: a) to explore perceived stress among undergraduate nursing students in Portugal and Spain during the COVID-19 pandemic outbreak; and b) to analyze several COVID-19 related factors and psychological issues that may be associated with perceived stress. A cross-sectional study was conducted with a convenience sample of Portuguese and Spanish undergraduate nursing students $(n=1075)$. The data gathered included demographic information, questions about COVID-19 related factors, and psychological issues. Data were analyzed using multiple logistic regression with a degree of significance at $\mathrm{p}<0.05$. High perceived stress scores were found in 558 participants (51.9\%). Students with high perceived stress most likely had a COVID-19 diagnosis in their household; their household income had been affected by the COVID-19 pandemic; experienced difficulty falling asleep or sleeping all night; consumed junk food in excess; neglected their appearance; felt headaches, stomach aches, and back pain; and lacked the patience or desire to exercise.

Additionally, high perceived stress was negatively associated with life satisfaction. The results provide evidence that infectious diseases, such as COVID-19, may significantly influence mental health. Further research should explore the long-term psychological effects of the COVID-19 pandemic among nursing students.

\section{INTRODUCTION}

The Coronavirus disease 2019 (COVID-19) caused by SARSCoV-2 was first identified in December 2019 in Wuhan, China, and by January 2020, the World Health Organization $^{1}$ had declared a public health emergency of international interest. At this point, the $\mathrm{WHO}^{1}$ warned the crisis was causing increased rates of stress and anxiety. In Portugal, the first case of COVID-19 was registered on March 2, $2020 .^{2}$ Shortly after that, on March 11 , COVID-19 was considered a pandemic by the WHO. At the time of writing (July $16,2020)$, more than 113 million people in 216 countries had been infected, and 580,045 had died from COVID-19.3 Portugal has vastly different COVID-19 infection and death rates than neighboring Spain, one of the worst-hit countries. By mid-July, while Portugal had 1,668 confirmed COVID-19 deaths (163 per million people), Spain had more than 47,051 deaths (608 per million inhabitants). ${ }^{4}$ The difference between both countries springs from a combination of factors, such as personal values, social and cultural background, gender, and education. ${ }^{5}$ The population's knowledge about a disease plays an important role in responding to an epidemic crisis and can impact collective attitudes. The media also plays a role in influencing public perception

\footnotetext{
a Corresponding author:

Carlos Laranjeira

School of Health Sciences - Polytechnic of Leiria

Campus 2 - Morro do Lena, Alto do Vieiro - Apartado 4137, 2411-901 Leiria, Portugal.

Email: carlos.laranjeira@ipleiria.pt
} 
of epidemics or pandemics, as they tend to bias perception by under- or over-estimating risk factors, morbidity, and mortality. ${ }^{6}$

All pandemics have a strong social, economic, and political impact. The COVID-19 pandemic has disrupted and brought significant stress to everyone's day-to-day life and may have exacerbated existing mental health conditions among young people. Many students had to rush home or find other housing after campuses were suddenly closed and concomitantly adapt quickly to distance learning technologies and settings. ${ }^{7}$ Many universities suspended in-person classes and evacuated students in response to the intensifying concerns surrounding COVID-19. These changes may have led to negative psychological consequences among university students. ${ }^{8}$ For whom the campus is homelike and welcoming, some students could have experienced intense feelings of hopelessness, frustration, anxiety, and betrayal. Some may have struggled with loneliness and isolation while sheltering in place because of disconnections from family and friends. 8 The rapid changes imposed upon university students, from the suspension of classes to the declaration of a state of emergency, may have triggered difficulties in adaptation and less positive emotional states. 9 Therefore, it is essential to explore the psychological implications of these circumstances.

A study in Japan addressing the economic impact of COVID-19 on well-being, fear, and panic behavior in society at large, concluded that there is an increased risk of adopting health risk behaviors, such as increased consumption of alcoholic beverages, illegal substances, and tobacco; a higher tendency for social isolation; and an increase in psychiatric illnesses, such as traumatic stress disorder, anxiety disorders, depression, somatization and decreased perception of one's health. ${ }^{9}$

Many students lost their jobs or prospects of getting a job during the pandemic while paying for their tuition and living expenses. Struggling with financial hardship increases the risk of mental health problems and lowers mental wellbeing. ${ }^{10}$ Students faced concerns and fears of becoming infected and transmitting COVID-19 to their family members when returning home. Given that the youth can be asymptomatic carriers, ${ }^{8}$ students may have been worried about placing their elder family members at increased risk of infection.

Attempting to explain stress and its impact, Lazarus and Folkman developed the transactional cognitive theory of stress and coping. ${ }^{11}$ According to their theory, a state of duress is a dynamic state of imbalance between oneself and one's surroundings when the latter is perceived as placing too significant a burden on one's well-being. ${ }^{12}$ People cope with stressors and feelings of stress in their lives in many different ways. Life satisfaction and hope provide a counterbalance to intrapersonal and interpersonal events that promote anxiety during periods of uncertainty and stress. In this sense, "hope (e.g., as faith) or hoping (e.g., actively focusing on reasons for feeling hopeful) act as emotion-focused coping strategies."13(p905)

Based on this theoretical framework, the continuous spread of the pandemic, strict isolation measures, and delayed college and university reopenings are expected to influence students' mental health around the world. As far as the authors of the present paper are aware, few studies have explored the impacts of COVID-19 and quarantine on the mental health status of university students, ${ }^{14,15}$ especially regarding the levels of perceived stress, life satisfaction, and hope.

AIMS

The primary purposes of this study were:

a) to explore perceived stress among undergraduate nursing students in Portugal and Spain during the COVID-19 pandemic outbreak;

b) to analyze several COVID-19-related factors and psychological issues that may be associated with perceived stress.

\section{METHODS}

\section{STUDY DESIGN AND SETTING}

A cross-sectional, descriptive design was used. Data were collected from nursing higher education institutions located in Portugal and Spain. These institutions were selected because they belong to a consortium of six institutions from Portugal and one from Spain (Valencia).

\section{SAMPLE AND DATA COLLECTION}

Data were collected using an online survey (in Portuguese and Spanish) created by the researchers specifically for this purpose, including all the items, protocol, and variables. School/University boards were contacted and agreed to participate. We used an internet platform to conduct the survey (Google Form). Participants were selected using snowball sampling, publicized on social networks. The participants were approached using social media, dedicated mailing lists linked to their institutions, and forums. The study involved only those students with internet access. Participants filled out the survey in an estimated mean time of 5 to $10 \mathrm{~min}$ utes. Volunteers received no compensation for their participation. Data was collected during the confinement period (April to May 2020) from undergraduate nursing students in Portugal and Spain $(\mathrm{n}=1075)$.

\section{MEASUREMENTS}

\section{A) DEMOGRAPHIC DATA}

Participants were asked to fill a demographic survey indicating their age, gender, year of study, and country.

\section{B) COVID-19 RELATED FACTORS}

This section included two yes/no questions about their covid-19 diagnosis and that of their household.

The question measured the impact of COVID-19 on family income, "Has your household income changed significantly with the current situation?" The responses were coded as 0 for "No," 1 for "Yes," and 2 for "prefer not to say."

Six statements measured confinement experience during the pandemic. Inspired by Virginia Henderson's Need Theory, ${ }^{16}$ these six items considered different personnel needs 
during confinement: “1. Difficulty falling asleep or sleeping all night; 2 . Consume junk food in excess (chocolates, chips, etc.); 3-neglect personal appearance; 4 . Have headaches, stomach aches, or back pain; 5 . Difficulty not hearing/reading news about COVID-19; 6. Lack patience or desire to exercise". The responses were coded as 0 for "No" and 1 for "Yes."

In addition, participants were asked to rate their level of concern about themselves and their relatives and friends becoming infected with the coronavirus, rated on a 5-point Likert scale ( $1=$ not worried at all, $5=$ very worried).

\section{C) PSYCHOLOGICAL FACTORS}

Life Satisfaction was measured by the question, "Given the changes caused by the current pandemic, how do you rate your life at the moment?". Answers were given on a ten-category Likert scale ranging from 1 ("worst possible life") to 10 ("best possible life").

Hope was measured using the 12-item Herth Hope Index [HHI] (Herth, 1992), which measures various dimensions of hope, based on Dufault and Martocchio's (1985) conceptual framework of hope. Each item used a 4-point Likert scale ranging from 1 (strongly disagree) to 4 (strongly agree). Items 3 and 6 were reverse-coded. The scale's global score ranges from 12 to 48, where a higher score denotes higher levels of hope. The Portuguese version was validated by Querido $^{17}$ and the Spanish version by Mesenguer, Fernández, and Soler. ${ }^{18}$ Cronbach's alpha for the present study was 0.848 .

Perceived stress was measured by a 10 -item perceived stress scale [PSS-10], ${ }^{19}$ which evaluates how unpredictable, uncontrollable, and overloaded respondents find their lives. Each item on the PSS-10 is rated on a 5-point Likert scale, ranging from 0 (never) to 4 (very often). The PSS-10 included six positively (items 1, 2, 3, 6, 9, and 10) and four negatively (items $4,5,7$, and 8) worded items. Negatively worded items were re-coded during analysis. Total scores range from 0 to 40, with higher scores indicating higher levels of perceived stress. Scores greater than or equal to the 80th percentile (cut-off value) are considered pathological and/or suggestive of suffering. Based on this assumption, the cut-off is 20 for men and 22 for women. The Portuguese version was validated by Trigo, Canudo, Branco, and Silva, ${ }^{20}$ and the Spanish version by Remor. ${ }^{21}$ In our study, the Cronbach's Alpha coefficient of the PSS-10 was 0.820 .

\section{ETHICAL CONSIDERATIONS}

The study was approved by a Research Ethics Committee (approval $\left.\mathrm{n}^{\circ} 74 / 2020\right)$. In all cases, ethical research standards under the Declaration of Helsinki were met by providing information on the project and requesting consent to participate. Students voluntarily completed the online data collection inquiry form. In addition, students were assured they were free to withdraw from the study at any point; participants were provided with an email to request information or confidential clinical support. Their responses remained confidential, and questionnaires were analyzed anonymously.

\section{STATISTICAL ANALYSES}

Descriptive statistics were performed to analyze participant characteristics. The descriptive analysis included frequency, central tendency, and dispersion measures.

Data were analyzed using multivariate logistic regression to measure the association of elevated perceived stress with the following variables: (1) demographics (age, gender, country); (2) COVID-19 related factors; and (3) psychological factors. For each variable, we calculated the odds ratio (OR) and 95\% CI using SPSS version 25 (IBM, Armonk, NY, USA). The alpha level was set at 0.05 to determine the level of significance.

\section{RESULTS}

\section{PARTICIPANT CHARACTERISTICS}

The demographic information of the 1075 participants (944 females and 131 males) is shown in Table 1, including their distribution over the four years of the undergraduate nursing courses. The mean sample age was $22.5(\mathrm{SD}=4.99)$, ranging from 18 to 53 years. There were 705 Portuguese students with a mean age of 21.7 years $(\mathrm{SD}=4.44)$ and 370 Spanish students with a mean age of 23.8 years $(S D=5.65)$. Most students were in their $4^{\text {th }}$ year of study $(29.7 \%)$, followed by the $1^{\text {st }}(26.1 \%), 3^{\text {rd }}(23.3 \%)$, and $2^{\text {nd }}$ years $(19 \%)$.

Table 2 displays data for COVID-19 related factors and psychological factors. Most students had no COVID-19 diagnosis, nor did any of their relatives $(n=1060$ and $n=1028$, respectively). Most reported no changes in household income (49.3\%), although 9.6\% did not respond. Regarding their confinement experience, the majority of students reported difficulties in sleep patterns (64\%) and unhealthy eating (54.4\%) and verbalized several somatic symptoms (67.1\%). Additionally, they indicated having remained motivated to perform physical activity (53.3\%) and adequately managing information regarding COVID-19 (63.3\%). Concern about contracting the coronavirus was lower than the fear their relatives and friends might become infected (3.3 points, $\mathrm{SD}=1.07$ vs. 4.5 points, $\mathrm{SD}=0.74$ ). At the time of sampling, the mean life satisfaction was 6.0 points $(S D=1.56)$, and the mean perceived stress (PSS-10) was $19.6(\mathrm{SD}=6.31)$. High perceived stress scores were found in 558 participants (51.9\%). The mean hope (HHI) was $37.5(\mathrm{SD}=5.12)$.

\section{LOGISTIC REGRESSION}

Portuguese nationality and female gender were both positively associated with high perceived stress (see Table 3). Conversely, age and hope were negatively associated with increased perceived stress. For example, for each unit increase on the hope scale, the OR of having high perceived pressure decreases by a factor of 0.172 (OR $0.828,95 \% \mathrm{CI}$ : 0.803-0.854). This means that a lower score on the hope scale is more likely associated with high perceived stress. After adjustment, the four variable-model was still positively associated with Portuguese nationality and female gender and negatively associated with hope.

After adjusting for confounds (including gender, age, country, and hope), subjects with high perceived stress (in comparison to subjects with low or moderate perceived 
Table 1. Sociodemographic characteristics by country and overall sample

\begin{tabular}{|c|c|c|c|c|c|c|}
\hline & \multicolumn{2}{|c|}{$\begin{array}{l}\text { Portuguese Students } \\
\qquad(n=705)\end{array}$} & \multicolumn{2}{|c|}{$\begin{array}{l}\text { Spanish Students } \\
\qquad(n=370)\end{array}$} & \multicolumn{2}{|c|}{$\begin{array}{l}\text { Overall sample } \\
\qquad(n=1075)\end{array}$} \\
\hline & $\mathrm{n}$ & $\%$ & $\mathrm{n}$ & $\%$ & $\mathrm{n}$ & $\%$ \\
\hline \multicolumn{7}{|l|}{ Gender } \\
\hline Female & 630 & 89.4 & 314 & 84.9 & 944 & 87.8 \\
\hline Male & 75 & 10.6 & 56 & 15.1 & 131 & 12.2 \\
\hline \multicolumn{7}{|l|}{ Year of study } \\
\hline $1^{\text {st }}$ year & 205 & 29.4 & 76 & 21.2 & 281 & 26.1 \\
\hline $2^{\text {nd }}$ year & 136 & 19.5 & 68 & 19.0 & 204 & 19.0 \\
\hline $3^{\text {rd }}$ year & 183 & 26.3 & 68 & 19.0 & 251 & 23.3 \\
\hline \multirow[t]{2}{*}{$4^{\text {th }}$ year } & 173 & 24.8 & 146 & 40.8 & 319 & 29.7 \\
\hline & mean & SD & mean & SD & mean & SD \\
\hline Age, years & 21.7 & 4.44 & 23.8 & 5.65 & 22.5 & 4.99 \\
\hline
\end{tabular}

$\mathrm{SD}=$ standard deviation

stress) had the strongest odds ratio for COVID-19 diagnosis in the household (OR=2.698; 95\% CI: 1.240-5.867); household income affected by COVID-19 pandemic (OR=1.519; 95\% CI: 1.141-2.021); difficulty falling asleep or sleeping all night (OR=2.469, 95\% CI 1.848-3.299); consumption of junk food in excess (OR=1.645; 95\% CI: 1.252-2.161); neglecting personal appearance (OR 1.569; 95\% CI: 1.177-2.092); experiencing headaches, stomach aches and back pain (OR=3.002; 95\% CI: 2.221-4.059); and lacking patience or desire to exercise ( $\mathrm{OR}=1.960 ; 95 \% \mathrm{CI}: 1.485-2.588)$. Additionally, high perceived stress was positively associated with concern of being infected $(\mathrm{OR}=1.336$; 95\% CI: 1.168-1.528), and fear of family or friend being infected $(\mathrm{OR}=1.420$; 95\% CI: $1.170-1.724)$; and negatively associated with life satisfaction (OR=0.729; 95\% CI: 0.660-0.806). Table 4 contains further information.

\section{DISCUSSION}

The present study was prompted by a lack of evidence on perceived stress among undergraduate nursing students during the COVID-19 pandemic. The results of this study indicate high levels of perceived stress. According to previous studies, students experience stress and anxiety. 15 Among university and college students in Portugal, 11.5\% suffered from moderate stress, while 19.3\% suffered from severe stress. ${ }^{22}$ In Spain, 25\% suffered from moderate or severe stress. ${ }^{23}$

A study by Maia and Dias ${ }^{24}$ indicated a significant increase in psychological disturbance during the pandemic period (between suspension of classes and the declaration of a state of emergency in Portugal) in the levels of anxiety, depression, and stress in Portuguese university students.

In a study by Rajkumar, ${ }^{25}$ symptoms related to depression (16\% to $28 \%$ ) and self-reported stress (8\%) were the most frequent psychological reactions associated with the pandemic COVID-19. According to other authors, anxiety is associated with sleep disorders. ${ }^{26}$

These results align with other international studies that analyzed the psychological effect of COVID-19 and other pandemics. ${ }^{27,28}$ The information transmitted by the media and the social emphasis on containment measures may have contributed to an increase in average scores. The massive transmission of fake news over social networks and media has created a chaotic and stressful atmosphere for students. Constantly monitoring the global situation and the increasing number of positive cases seems to have increased anxiety, depression, and stress among university students, although this group was thought not to have a high risk of lethality. ${ }^{28,29}$

Numerous empirical studies found that information helps an individual cope with a variety of personal and collective stressors. Savitsky, Findling, Ereli, and Hendel ${ }^{15}$ believe that, in the case of the COVID-19 pandemic, seeking information might increase anxiety given the multiple sources and overflow of information, sometimes conveying contradictory information. Information should be provided without sensationalism or disturbing images, ${ }^{30}$ offering opportunities for individuals to tackle their fear themselves. People should be advised to restrict their exposure to the media coverage of the COVID-19 crisis and avoid sensational media, which may enhance stress and decrease wellbeing.

Our results are consistent with Chinese studies showing that more than $25 \%$ of the general population had moderate to severe somatic symptoms associated with stress during the coronavirus pandemic. ${ }^{27,31}$ An appropriate level of stress can improve the body's resistance and serve as a defense mechanism when stress is out of control. Still, stress has a negative effect on the autonomic nervous system and cortex. This can lead to psychosomatic and somatic symptoms and, in turn, to psychological problems and mental illness. ${ }^{32}$ Thus, we find a negative relationship between hope and perceived stress. Highly hopeful people are thought to experience less stress and more life satisfaction. Different studies have reported positive motivation levels, interest, effort, and positive emotions among students in their academic lives, and a negative relationship between stress and hope. 33,34 
Table 2. COVID-19 related factors and psychological issues by country and overall sample

\begin{tabular}{|c|c|c|c|c|c|c|}
\hline & \multicolumn{2}{|c|}{$\begin{array}{l}\text { Portuguese Students } \\
(\mathrm{n}=705)\end{array}$} & \multicolumn{2}{|c|}{$\begin{array}{l}\text { Spanish Students } \\
(n=370)\end{array}$} & \multicolumn{2}{|c|}{$\begin{array}{l}\text { Overall sample } \\
(n=1075)\end{array}$} \\
\hline & $\mathrm{N}$ & $\%$ & $\mathrm{n}$ & $\%$ & $\mathrm{~N}$ & $\%$ \\
\hline \multicolumn{7}{|l|}{ COVID-19 diagnosis (own) } \\
\hline Yes & 5 & 0.7 & 10 & 2.7 & 15 & 1.4 \\
\hline No & 700 & 99.3 & 360 & 97.3 & 1060 & 98.6 \\
\hline \multicolumn{7}{|l|}{ COVID-19 diagnosis (other in the household) } \\
\hline Yes & 23 & 3.3 & 19 & 5.2 & 42 & 3.9 \\
\hline No & 681 & 96.7 & 347 & 94.8 & 1028 & 95.6 \\
\hline \multicolumn{7}{|l|}{ COVID-19 impact on household income } \\
\hline Yes & 273 & 38.7 & 169 & 45.7 & 442 & 41.1 \\
\hline No & 353 & 50.1 & 177 & 47.8 & 530 & 49.3 \\
\hline Prefer not to say & 79 & 11.2 & 24 & 6.5 & 103 & 9.6 \\
\hline \multicolumn{7}{|l|}{ Compared with pre-COVID-19 period: } \\
\hline \multicolumn{7}{|l|}{ Difficulty falling asleep or sleeping all night } \\
\hline Yes & 416 & 59.0 & 272 & 73.5 & 688 & 64.0 \\
\hline No & 289 & 41.0 & 98 & 26.5 & 387 & 36.0 \\
\hline \multicolumn{7}{|l|}{$\begin{array}{l}\text { Consume junk food in excess (chocolates, chips, } \\
\text { etc.) }\end{array}$} \\
\hline Yes & 424 & 60.1 & 161 & 43.5 & 585 & 54.4 \\
\hline No & 281 & 39.9 & 209 & 56.5 & 490 & 45.6 \\
\hline \multicolumn{7}{|l|}{ Neglect personal appearance } \\
\hline Yes & 236 & 33.5 & 144 & 38.9 & 380 & 35.3 \\
\hline No & 469 & 66.5 & 226 & 61.1 & 695 & 64.7 \\
\hline \multicolumn{7}{|l|}{ Have headaches, stomach aches, or back pain } \\
\hline Yes & 434 & 61.6 & 287 & 77.6 & 721 & 67.1 \\
\hline No & 271 & 38.4 & 83 & 22.4 & 354 & 32.9 \\
\hline \multicolumn{7}{|l|}{$\begin{array}{l}\text { Difficulty not hearing/reading news about } \\
\text { COVID-19 }\end{array}$} \\
\hline Yes & 185 & 26.2 & 210 & 56.8 & 395 & 36.7 \\
\hline No & 520 & 73.8 & 160 & 43.2 & 680 & 63.3 \\
\hline \multicolumn{7}{|l|}{ Lack patience or desire to exercise } \\
\hline Yes & 338 & 47.9 & 164 & 44.3 & 502 & 46.7 \\
\hline \multirow[t]{2}{*}{ No } & 367 & 52.1 & 206 & 55.7 & 573 & 53.3 \\
\hline & median & P25-P75 & median & P25-P75 & median & P25-75 \\
\hline Fear of being infected, $1-5$ pts & 3 & $3-4$ & 3 & $2-3$ & 3 & $2-4$ \\
\hline Fear of family or friends being infected, $1-5$ pts & 5 & $4-5$ & 5 & $4-5$ & 5 & $4-5$ \\
\hline Life satisfaction, 1-10 pts & 6 & $5-7$ & 6 & $5-7$ & 6 & $5-7$ \\
\hline HHI-12, 12-48 pts & 37 & $35-41$ & 38 & $35-41$ & 37 & $35-41$ \\
\hline PSS-10, 0-40 pts & 20 & $16-25$ & 19 & $15-23$ & 20 & $15-24$ \\
\hline Levels of PSS-10 & $\mathrm{n}$ & $\%$ & $\mathrm{n}$ & $\%$ & $\mathrm{n}$ & $\%$ \\
\hline Low or moderate perceived stress & 321 & 45.5 & 196 & 53.0 & 517 & 48.1 \\
\hline High perceived stress* & 384 & 54.5 & 174 & 47.0 & 558 & 51.9 \\
\hline
\end{tabular}

P25-P75 = percentile 25 and percentile 75 ; pts = points

* Higher than percentile 80 ( $\geqslant 20$ points for men and $\geqslant 22$ points for women)

Findings regarding gender and perceived stress revealed that male and female participants differ significantly: females report higher feelings of stress than males. These results could perhaps be explained by Anbumalar, Dorathy,
Jaswanti, Priya, and Reniangelin, ${ }^{35}$ and Eisenbarth, ${ }^{36}$ who posited that females are more emotional as compared to males and face several burdens in everyday life as a result of social status and roles relative to men. In addition, males 
Table 3. Association between levels of perceived stress, sociodemographic characteristics, and hope score

\begin{tabular}{|c|c|c|c|c|}
\hline & \multicolumn{2}{|c|}{ High Perceived Stress ${ }^{a}$} & \multicolumn{2}{|c|}{ High Perceived Stress a } \\
\hline & OR $(95 \% \mathrm{Cl})$ & $p$-value & $\operatorname{adjOR}(95 \% \mathrm{Cl})^{b}$ & $p$-value \\
\hline \multicolumn{5}{|l|}{ Country } \\
\hline Portugal & $1.348(1.047 ; 1.734)$ & 0.020 & $1.358(1.020 ; 1.807)$ & 0.036 \\
\hline Spain & 1.0 & & 1.0 & \\
\hline \multicolumn{5}{|l|}{ Gender } \\
\hline Male & 1.0 & & 1.0 & \\
\hline Female & $2.364(1.609 ; 3.472)$ & $<0.001$ & $2.938(1.905 ; 4.529)$ & $<0.001$ \\
\hline Age, years & $0.956(0.934 ; 0.981)$ & 0.001 & $0.979(0.951 ; 1.008)$ & 0.161 \\
\hline $\mathrm{HHI}, 12-48 \mathrm{pts}$ & $0.828(0.803 ; 0.854)$ & $<0.001$ & $0.822(0.797 ; 0.849)$ & $<0.001$ \\
\hline
\end{tabular}

OR = Odds ratio; $95 \% \mathrm{CI}=95 \%$ confidence interval HHI = Herth Hope Index

${ }^{a}$ Low or moderate perceived stress was used as the reference category.

$\mathrm{b}$ OR adjusted for gender, age, and country.

are expected to live up to specific social expectations, where sharing feelings is perceived as a sign of weakness.

The current study also investigated predictors of perceived stress during the coronavirus outbreak. Based on the literature, we expected that individual difference variables (COVID-19 impact on household income, COVID-19 diagnosis, confinement experience, hope, and life satisfaction) would predict increased perceived stress. Additionally, we expected that higher personal relevance of the threat (for both oneself and loved ones) would indicate increased stress levels. In line with these predictions, we found that all these factors predicted higher stress scores.

Concerning the experience of confinement during COVID-19, students chose negative coping strategies, such as unhealthy eating (non-nutritious food) or neglecting their self-care, practices that are ineffective and may worsen the level of stress. ${ }^{15,37}$

Positive ways to cope with stress would include regular exercise, regular sleep routines, and healthy eating. Further skill development is mandatory, such as practicing relaxation techniques to reduce the effects of emotional, physical, or mental stress; or striving to keep a positive attitude and maintain a sense of hope for the future. Although this may be difficult, thinking positive thoughts and focusing on positive images for the future can help combat anxiety, depression, and overwhelming sadness. ${ }^{38}$

Another way to manage the fear of the coronavirus could focus on the perceived risk of the virus for loved ones. This was the strongest predictor of high perceived stress in our sample. This concern can be mitigated by providing the public with clear information about risks and taking (additional) steps to protect vulnerable groups from infection. Clear communication may also help motivate people to follow government guidelines. Those who perceive a low risk of disease may ignore social distancing guidelines while increasing health risks for their loved ones.

Current research has also shown that fear of coronavirus infection and experienced stress are negatively linked to life satisfaction. Ahorsu et al. ${ }^{39}$ indicated that fear of COVID-19 increases stress among the general public. Constant information about confirmed deaths globally and the growing number of cases increase the level of fear of COVID-19 and lead to stress and a negative impact on life satisfaction. ${ }^{40}$

According to the assumption of transactional cognitive theory of stress and coping, ${ }^{11}$ prolonged stress may be accompanied by loss of resources. The pandemic threat is a source of stress and impedes effective coping, affecting resources such as hope and life satisfaction. The "revival of hope in intensely stressful situations depends at least in part on cognitive coping processes. In turn, the person's capacity to sustain coping with intensely stressful situations over time depends at least in part on having hope concerning the desired outcome."13(p903) For that reason, the novel coronavirus pandemic can be the moment the world pushes back against fear and isolationism and turns instead towards hope, solidarity, and a shared sense of global community.

\section{LIMITATIONS AND SUGGESTIONS}

This study is not without limitations. The most important is related to the inclusion of more students from Portuguese than Spanish higher education institutions. Therefore, representative data from both countries should be considered in future research. Second, this study used a cross-sectional design, which cannot provide strong evidence for causality. Thus, further research should use a longitudinal design. Third, this study used self-report questionnaires, which have issues with subjectivity and reliability. Also, massive online assessment, although highly efficient, may provide data of a lower quality than that obtained by face-to-face interviews.

Given that few cases of students diagnosed with COVID-19 have been identified, it would be helpful to analyze in-depth the lived experience of survivors using phenomenological methods.

Despite these limitations, our study provides further evidence for a clear trend of significant symptoms of anxiety and stress among the young population, which must be explored in depth as a target of preventive interventions in mental health disorders. 
Table 4. Factors associated with high perceived stress (PSS $\geqslant 20$ points for men and $\geqslant 22$ points for women)

Overall sample $(n=1075)$

\begin{tabular}{|c|c|c|}
\hline & $\begin{array}{l}\text { High Perceived Stress }{ }^{a} \\
\text { adjusted OR }(95 \% \mathrm{Cl})^{b}\end{array}$ & $p$-value \\
\hline \multicolumn{3}{|l|}{ COVID-19 diagnosis (own) } \\
\hline Yes & $2.854(0.752 ; 10.831)$ & 0.123 \\
\hline No & 1.0 & \\
\hline \multicolumn{3}{|l|}{ COVID-19 diagnosis (other in the household) } \\
\hline Yes & $2.698(1.240 ; 5.867)$ & 0.012 \\
\hline No & 1.0 & \\
\hline \multicolumn{3}{|l|}{ COVID-19 impact on household income } \\
\hline Yes & $1.519(1.141 ; 2.021)$ & 0.004 \\
\hline No & 1.0 & \\
\hline \multicolumn{3}{|l|}{ Compared with pre-COVID-19 period: } \\
\hline \multicolumn{3}{|l|}{ Difficulty falling asleep or sleeping all night } \\
\hline Yes & $2.469(1.848 ; 3.299)$ & $<0.001$ \\
\hline No & 1.0 & \\
\hline \multicolumn{3}{|l|}{ Consume junk food in excess (chocolates, chips, etc.) } \\
\hline Yes & $1.645(1.252 ; 2.161)$ & $<0.001$ \\
\hline No & 1.0 & \\
\hline \multicolumn{3}{|l|}{ Neglect personal appearance } \\
\hline Yes & $1.569(1.177 ; 2.092)$ & 0.002 \\
\hline No & 1.0 & \\
\hline \multicolumn{3}{|l|}{ Have headaches, stomach aches, or back pain } \\
\hline Yes & $3.002(2.221 ; 4.059)$ & $<0.001$ \\
\hline No & 1.0 & \\
\hline \multicolumn{3}{|c|}{ Difficulty not hearing/reading news about COVID-19 } \\
\hline Yes & $1.071(0.800 ; 1.434)$ & 0.645 \\
\hline No & 1.0 & \\
\hline \multicolumn{3}{|l|}{ Lack patience or desire to exercise } \\
\hline Yes & $1.960(1.485 ; 2.588)$ & $<0.001$ \\
\hline No & 1.0 & \\
\hline Fear of being infected, $1-5 \mathrm{pts}$ & $1.336(1.168 ; 1.528)$ & $<0.001$ \\
\hline Fear of family or friends being infected, $1-5 \mathrm{pts}$ & $1.420(1.170 ; 1.724)$ & $<0.001$ \\
\hline Life satisfaction, 1-10 pts & $0.729(0.660 ; 0.806)$ & $<0.001$ \\
\hline
\end{tabular}

OR $=$ Odds ratio $; 95 \% \mathrm{CI}=95 \%$ confidence interval; pts = points

${ }^{a}$ Low or moderate perceived stress was used as the reference category.

$\mathrm{b}$ OR adjusted for gender, age, country, and hope (HHI)

\section{IMPLICATIONS}

College students are especially prone to feelings of loneliness, and they experience higher rates of anxiety and depression than the general population. During this current period of social isolation, uncertainty, and abrupt transitions, these feelings are prone to worsen further. Removing their social support system and lack of extracurricular activities at their school can cause students to feel less connected with their friends, organizations, and hobbies. In addition, students face uncertainty about their future, their health, and the health of their friends and loved ones. The situation they live in is stressful and anxiety-provoking. There is a constant fear of the unknown and a sense of loss of control, making them especially vulnerable to developing mental health issues. For this new COVID-19 situation, Xiang et al. ${ }^{32(p 229)}$ suggest that three main factors should be considered when developing mental health strategies: “1) multidisciplinary mental health teams; 2) clear communication involving regular, accurate updates on the COVID-19 outbreak; and 3) establishing safe psychological counseling services (for example, via electronic devices or apps)".

Other implications for nursing educators include helping students manage friendships and relationships, problem- 
solving, decision making, and identifying and managing emotions in this new paradigm. Faculty can emphasize that nursing students are not alone and can provide guidance and mentorship, namely regarding study skills, time management, or how to handle anxiety and stress related to new digital learning and communication formats. Faculty can create virtual drop-in opportunities during the week for students to discuss problems or concerns about coursework, study, academic or other challenges.

The need to remain physically distant does not have to mean a loss of social contact. Thus, students should be encouraged to nurture their friendships and stay in communication with their classmates. Some avenues for strengthening social connectedness might include online study groups or online study/accountability partners.

Higher education institutions must be prepared to identify students at risk for mental health problems and/or suicidal behavior and promote emotional health awareness among those who interact with students most frequently, from faculty members to other students. Thakur and Jain argue that uncertainty, feelings of hopelessness, and a sense of worthlessness may increase suicide rates. ${ }^{41}$ When communicating with students via phone, email, text, or social media platforms, faculty members and administrators can employ principles of active listening. If students express concerns, they must be heard carefully at three levels: the content of what they are saying, their emotions, and their behaviors in response to those thoughts and feelings. Students who need help but are reluctant or unsure of how to get it may have more incredible difficulty reaching out and accessing care. In this new environment, counseling centers can open a virtual discussion group, specifically for students to talk about what's going on and how they feel.

University professionals can also monitor and respond to some of the posts students share on social media pages. That will enable students to crowdsource questions that faculty members may not be able to answer themselves. For the most vulnerable nursing students, education is lifesaving. Not only does it provide safety and protection, but importantly it also instills hope for a brighter future.

\section{CONCLUSION}

In sum, this study found that psychological and somatic health problems remain a severe issue among undergraduate nursing students during a public health emergency. Our results show that elevated perceived stress was found among those students worried about being infected and fearful a family member or friend might become infected. Lower perceived stress was associated with having higher life satisfaction.

These results highlight the importance of exploring psychological distress among nursing students as it may have long-term implications for personal welfare. Amidst the stress that students continue to endure, we can find comfort in stories of hope and solidarity. We should value the positive, encouraging lessons that are emerging for our postCOVID world.

\section{CONFLICTS OF INTEREST}

The authors declared no conflict of interest with respect to the authorship and/or publication of this article.

\section{ACKNOWLEDGEMENTS}

We acknowledge all the students who participated in the online survey to make this study possible.

\section{FUNDING}

This work was funded by Portuguese national funds provided by Fundação para a Ciência e Tecnologia (FCT) (UIDB/ 05704/2020 and UIDP/05704/2020).

Submitted: June 01, 2021 EST, Accepted: June 02, 2021 EST 


\section{REFERENCES}

1. World Health Organization. Mental health and psychosocial considerations during the COVID-19 outbreak. Published 2020. https://www.who.int/docs/ default-source/coronaviruse/mental-health-considera tions.pdf

2. Nogueira PJ, De Araújo Nobre M, Nicola PJ, Furtado C, Vaz Carneiro A. Excess Mortality Estimation During the COVID-19 Pandemic: Preliminary Data from Portugal. Acta Med Port. 2020;33(6):376-383. do i:10.20344/amp. 13928

3. World Health Organization. Numbers at glance. Published 2020. https://www.who.int/emergencies/di seases/novel-coronavirus-2019?gclid=Cj0KCOjw9b_4 BRCMARIsADMUIyriXDTki_UICJIOkprBmI79gUtwUN mW-YIvP0Ci1vIq09xgMzyEn-waAjgBEALw wcB

4. World Health Organization. Coronavirus disease (COVID-19) pandemic. Published 2020. https://www.e uro.who.int/en/health-topics/health-emergencies/cor onavirus-covid-19

5. Organization for Economic Co-operation and Development (OECD). The territorial impact of COVID-19: Managing the crisis across levels of government. Published 2020. http://www.oecd.org/co ronavirus/policy-responses/the-territorial-impact-ofcovid-19-managing-the-crisis-across-levels-of-gover nment-d3e314e1/

6. Young ME, Norman GR, Humphreys KR. Medicine in the popular press: the influence of the media on perceptions of disease. PLoS One.

2008;3(10):e3552-10. doi:10.1371/journal.pone.00035 $\underline{52}$

7. Blankenberger B, Williams AM. COVID and the impact on higher education: The essential role of integrity and accountability. Administrative Theory \& Praxis. Published online 2020:1-20. doi:10.1080/1084 1806.2020.1771907

8. Zhai Y, Du X. Addressing collegiate mental health amid COVID-19 pandemic. Psychiatry Research. 2020;288:113003. doi:10.1016/j.psychres.2020.113003

9. Grubic N, Badovinac S, Johri AM. Student mental health in the midst of the COVID-19 pandemic: A call for further research and immediate solutions. Int J Soc Psychiatry. 2020;66(5):517-518. doi:10.1177/00207640 $\underline{20925108}$
10. McDaid S, Kousoulis A. Tackling social inequalities to reduce mental health problems: How everyone can flourish equally. Published 2020. http s://www.mentalhealth.org.uk/publications/tackling-s ocial-inequalities-reduce-mental-health-problems

11. Stangor C, Wallinga J. Introduction to Psychology. Published 2014. https://opentextbc.ca/introductionto psychology/

12. Shacham M, Hamama-Raz Y, Kolerman R, Mijiritsky O, Ben-Ezra M, Mijiritsky E. COVID-19 Factors and Psychological Factors Associated with Elevated Psychological Distress among Dentists and Dental Hygienists in Israel. IJERPH. 2020;17(8):2900. doi:10.3390/ijerph17082900

13. Folkman S. Stress, coping, and hope. PsychoOncology. 2010;19(9):901-908. doi:10.1002/pon.1836

14. Cao W, Fang Z, Hou G, et al. The psychological impact of the COVID-19 epidemic on college students in China. Psychiatry Research. 2020;287:112934. doi:1 0.1016/j.psychres.2020.112934

15. Savitsky B, Findling Y, Ereli A, Hendel T. Anxiety and coping strategies among nursing students during the covid-19 pandemic. Nurse Education in Practice. 2020;46:102809. doi:10.1016/j.nepr.2020.102809

16. Wills E, Mcewen M. Bases Teóricas de Enfermagem [Theoretical Bases of Nursing]. Artmed Editora; 2015.

17. Querido A. A promoção da esperança em fim-devida: avaliação da efetividade de um programa de intervenção em pessoas com doença crónica avançada e progressiva [The promotion of hope at the end-oflife: evaluation of the effectiveness of an intervention program in people with advanced and progressive chronic disease]. Published online 2013.

18. Meseguer M, Fernández M, Soler M. Propiedades Psicométricas de la escala abreviada de Esperanza de Herth (HHI) en una muestra multiocupacional de la Región de Murcia [Psychometric properties of Herth's short scale (HHI) in a multioccupational sample from Murcia]. In: Comunicación Presentada al I Congreso de Centros Universitarios de Relaciones Laborales y Ciencias Del Trabajo. ; 2013.

19. Cohen S, Kamarck T, Mermelstein R. A global measure of perceived stress. Journal of Health and Social Behavior. 1983;24(4):385-396. doi:10.2307/2136 $\underline{404}$ 
20. Trigo M, Canudo N, Branco F, Silva D. Estudo das propriedades psicométricas da Perceived Stress Scale (PSS) na população portuguesa. Psychologica. 2010;53:353-378. doi:10.14195/1647-8606_53 17

21. Remor E. Psychometric properties of a European Spanish version of the Perceived Stress Scale (PSS). Span J Psychol. 2006;9(1):86-93. doi:10.1017/s113874 1600006004

22. Firmino C, Valentim O, Sousa L, Antunes A, Marques F, Simões C. Stress, anxiety and depression in Portuguese nursing students. In: Sequeira C, Carvalho JC, Sá L, Seabra P, Silva M, Araújo O, eds. IX Congresso Internacional ASPESM: Saúde Mental Para Todos. ASPESM; 2018:109-118.

23. Mirón J, Goldberg X, López-Sola C, et al. Perceived Stress, Anxiety and Depression Among Undergraduate Students: An Online Survey Study. Journal of Depression and Anxiety. 2019;8:330. doi:1 $\underline{0.4172 / 2167-1044.1000330}$

24. Maia BR, Dias PC. Anxiety, depression and stress in university students: the impact of COVID-19. Estudos de Psicologia (Campinas). 2020;37:e200067. do i:10.1590/1982-0275202037e200067

25. Rajkumar RP. COVID-19 and mental health: A review of the existing literature. Asian Journal of Psychiatry. 2020;52:102066. doi:10.1016/i.ajp.2020.10 $\underline{2066}$

26. Xiao H, Zhang Y, Kong D, Li S, Yang N. The Effects of Social Support on Sleep Quality of Medical Staff Treating Patients with Coronavirus Disease 2019 (COVID-19) in January and February 2020 in China. Med Sci Monit. 2020;26:e923549. doi:10.12659/msm.9 23549

27. Wang C, Pan R, Wan X, et al. Immediate Psychological Responses and Associated Factors during the Initial Stage of the 2019 Coronavirus Disease (COVID-19) Epidemic among the General Population in China. IJERPH. 2020;17(5):1729. doi:1 $\underline{\text { 0.3390/ijerph17051729 }}$

28. Weiss P, Murdoch DR. Clinical course and mortality risk of severe COVID-19. Lancet. 2020;395(10229):1014-1015. doi:10.1016/s0140-673 6(20)30633-4

29. Zhou F, Yu T, Du R, et al. Clinical course and risk factors for mortality of adult inpatients with COVID-19 in Wuhan, China: a retrospective cohort study. Lancet. 2020;395(10229):1054-1062. doi:10.101 6/s0140-6736(20)30566-3
30. Garfin DR, Silver RC, Holman EA. The novel coronavirus (COVID-2019) outbreak: Amplification of public health consequences by media exposure. Health Psychology. 2020;39(5):355-357. doi:10.1037/h ea0000875

31. Qiu J, Shen B, Zhao M, Wang Z, Xie B, Xu Y. A nationwide survey of psychological distress among Chinese people in the COVID-19 epidemic: implications and policy recommendations. Gen Psych. 2020;33(2):e100213. doi:10.1136/gpsych-2020-10021 $\underline{3}$

32. Xiang YT, Yang Y, Li W, et al. Timely mental health care for the 2019 novel coronavirus outbreak is urgently needed. Lancet Psychiatry. 2020;7(3):228-229. doi:10.1016/s2215-0366(20)3004 $\underline{6-8}$

33. Lee C, Hwang Y. The Effects of Hope, Emotional Intelligence, and Stress on the Self-esteem of Rural Elementary School Students in Korea: The Mediating Effect of Social Support. Indian Journal of Science and Technology. 2016;9(26):1-7. doi:10.17485/ijst/2016/v9i 26/97278

34. Runcan P, Iovu M. Emotional Intelligence and Life Satisfaction in Romanian University Students: The Mediating Role of Self-Esteem and Social Support. Revista de Cercetare si Interventie Sociala. 2013;40:137-148.

35. Anbumalar C, Dorathy A, Jaswanti V, Priya D, Reniangelin D. Gender Differences in Perceived Stress levels and Coping Strategies among College Students. The International Journal of Indian Psychology. 2017;4(4):22-33. doi:10.25215/0404.103

36. Eisenbarth C. Coping with stress: gender differences among college students. College Student Journal. 2019;53(2):151.

37. Zachary Z, Brianna F, Brianna L, et al. Selfquarantine and weight gain related risk factors during the COVID-19 pandemic. Obesity Research \& Clinical Practice. 2020;14(3):210-216. doi:10.1016/j.orcp.202 $\underline{0.05 .004}$

38. World Health Organization. Mental health and psychosocial considerations during the COVID-19 outbreak. Published 2020. https://www.who.int/docs/ default-source/coronaviruse/mental-health-considera tions.pdf?sfvrsn=6d3578af_2

39. Ahorsu DK, Lin CY, Imani V, Saffari M, Griffiths MD, Pakpour AH. The Fear of COVID-19 Scale: Development and Initial Validation. Int J Ment Health Addiction. Published online 2020:1-9. doi:10.1007/s11 469-020-00270-8 
40. Satici B, Gocet-Tekin E, Deniz ME, Satici SA. Adaptation of the Fear of COVID-19 Scale: Its Association with Psychological Distress and Life Satisfaction in Turkey. Int J Ment Health Addiction. Published online May 8, 2020:1-9. doi:10.1007/s1146 9-020-00294-0
41. Thakur V, Jain A. COVID 2019-suicides: A global psychological pandemic. Brain, Behavior, and Immunity. 2020;88:952-953. doi:10.1016/j.bbi.2020.0 4.062 